Supporting information for

\title{
The Dependence of Carbohydrate-Aromatic Interaction Strengths on the Structure of the Carbohydrate
}

Che-Hsiung Hsu, ${ }^{\dagger \dagger}$ Sangho Park, ${ }^{\S}$ David E. Mortenson, ${ }^{\dagger}$ B. Lachele Foley, ${ }^{\#}$ Xiaocong Wang, ${ }^{\#}$ Robert J. Woods, ${ }^{\#}$ David A. Case,

Evan T. Powers, ${ }^{\hbar} *$ Chi-Huey Wong, $,=, \perp, *$ H. Jane Dyson, ${ }^{\S, *}$ Jeffery W. Kelly $y^{\dagger, \star, \perp * *}$

${ }^{\dagger}$ Department of Molecular and Experimental Medicine, The Scripps Research Institute, La Jolla, CA 92037, USA.

Department of Chemistry, The Scripps Research Institute, La Jolla, CA 92037, USA.

${ }^{\S}$ Department of Integrative Structural and Computational Biology, The Scripps Research Institute, La Jolla, CA 92037, USA.

${ }^{\#}$ Complex Carbohydrate Research Center, University of Georgia, 315 Riverbend Road, Athens, Georgia 30602, USA.

"Department of Chemistry and Chemical Biology, Rutgers University, Piscataway, NJ 08854.

${ }^{-}$Genomics Research Center, Academia Sinica, Taipei 115, Taiwan.

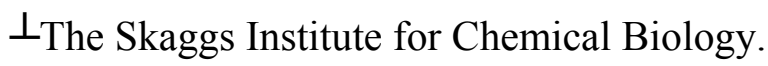




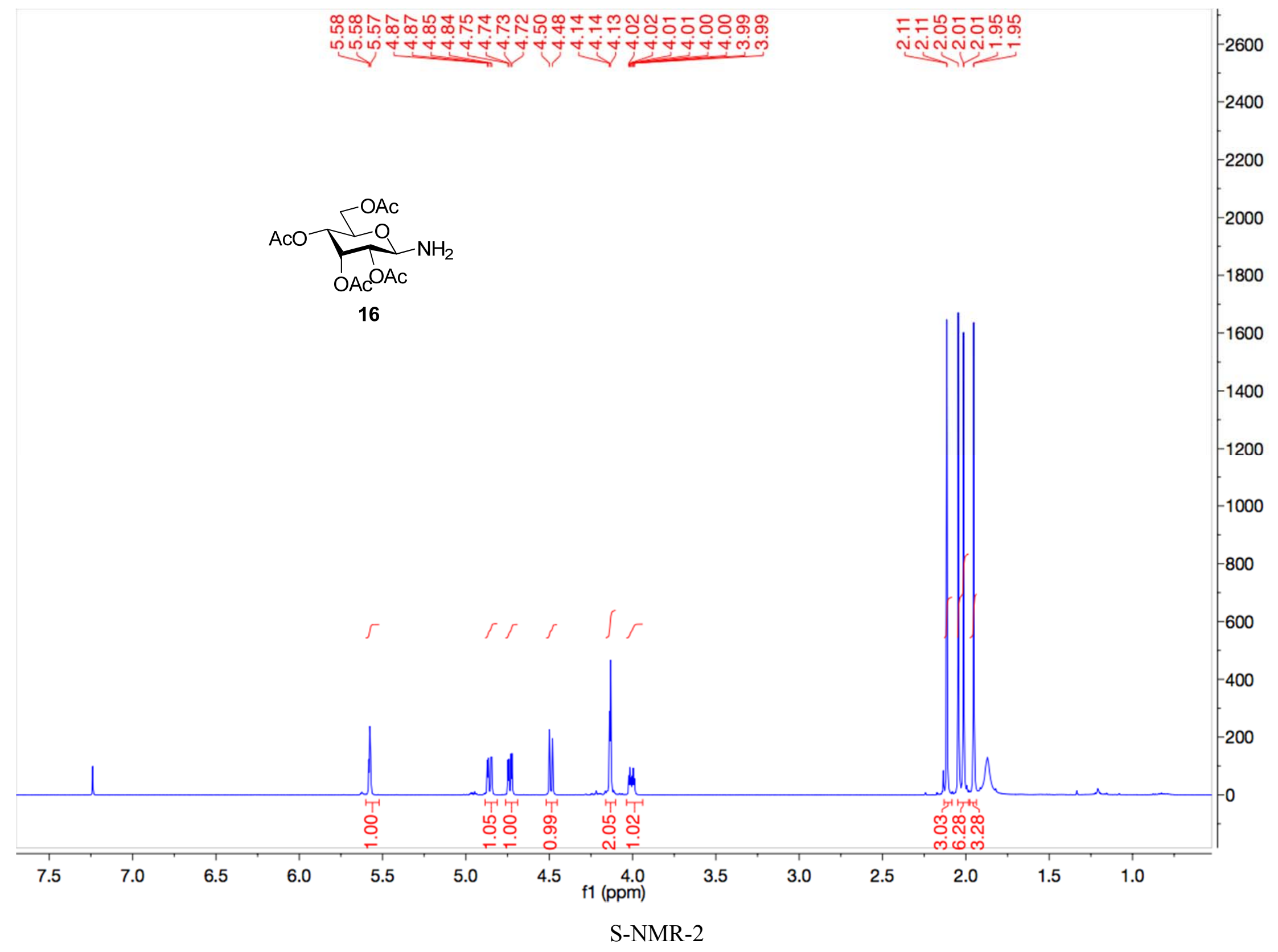




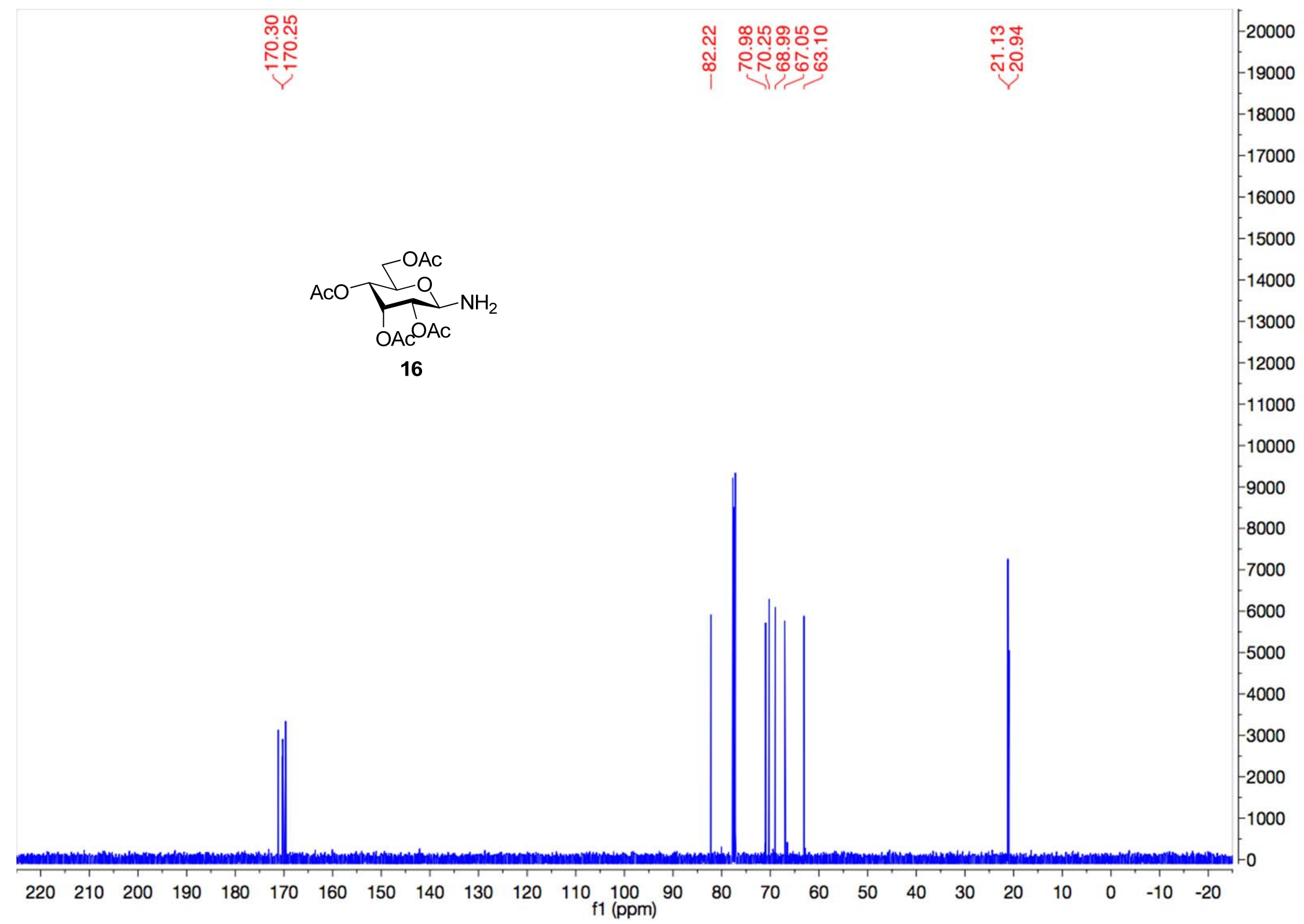

S-NMR-3 


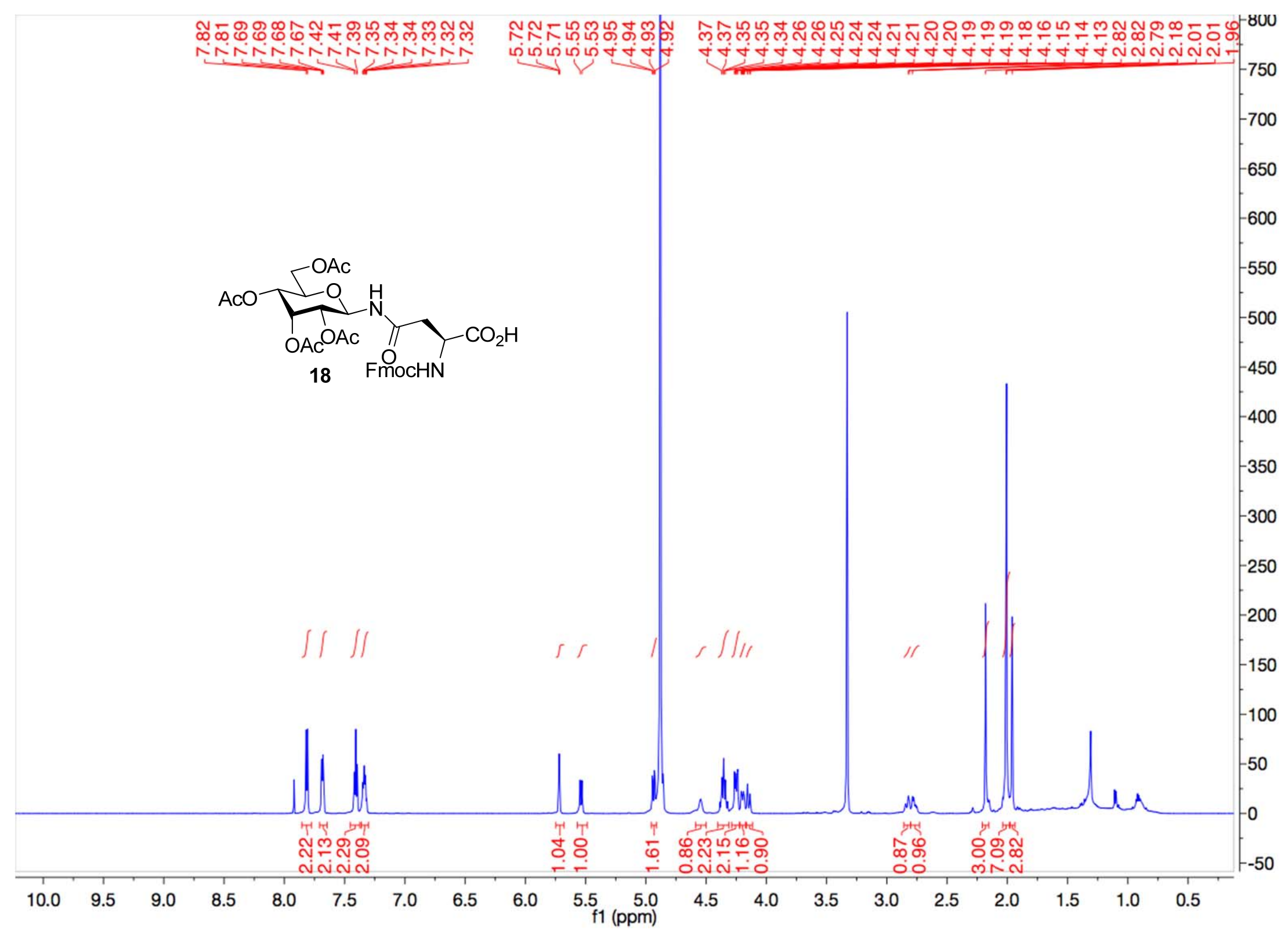

S-NMR-4 


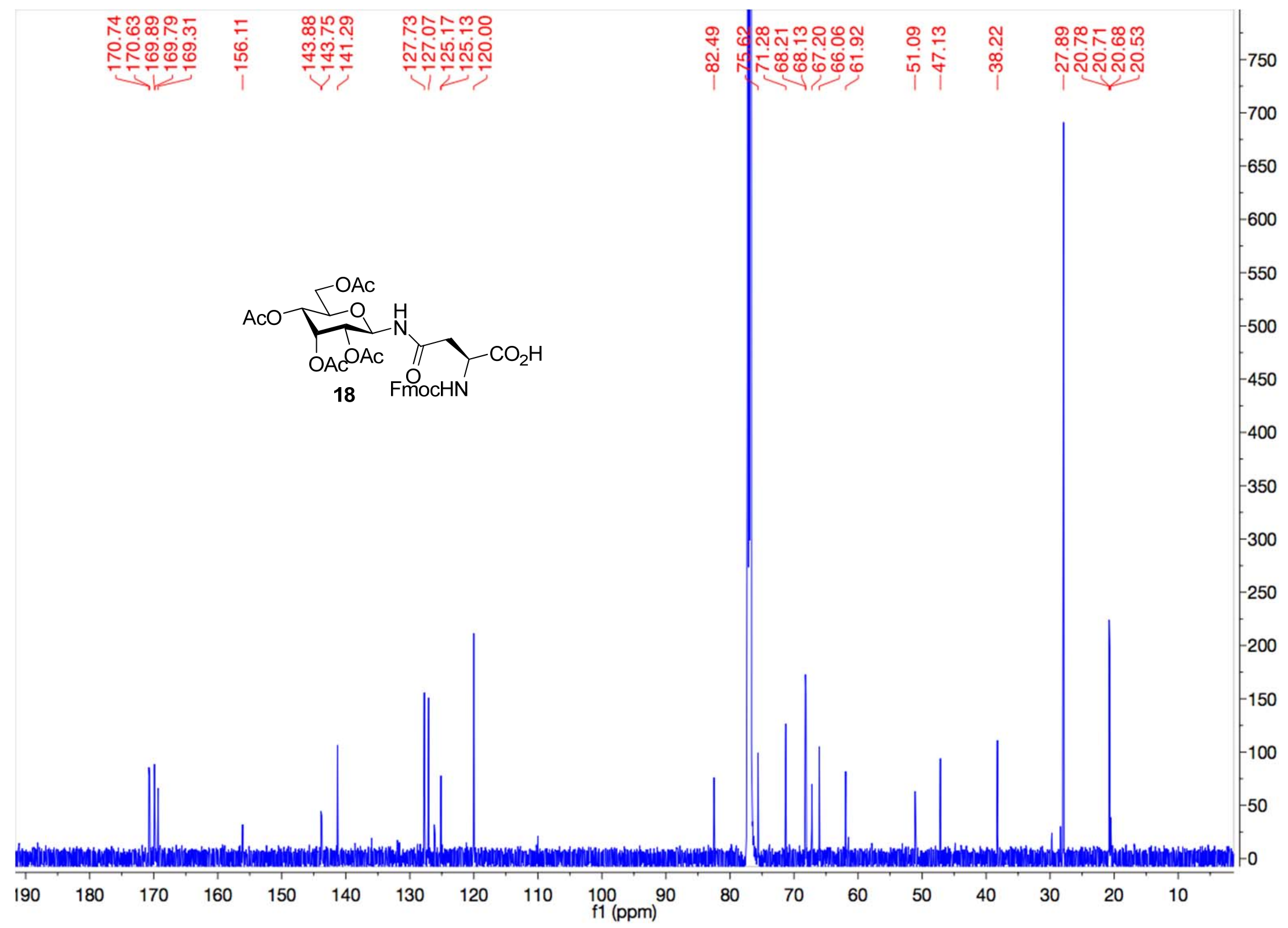

S-NMR-5 


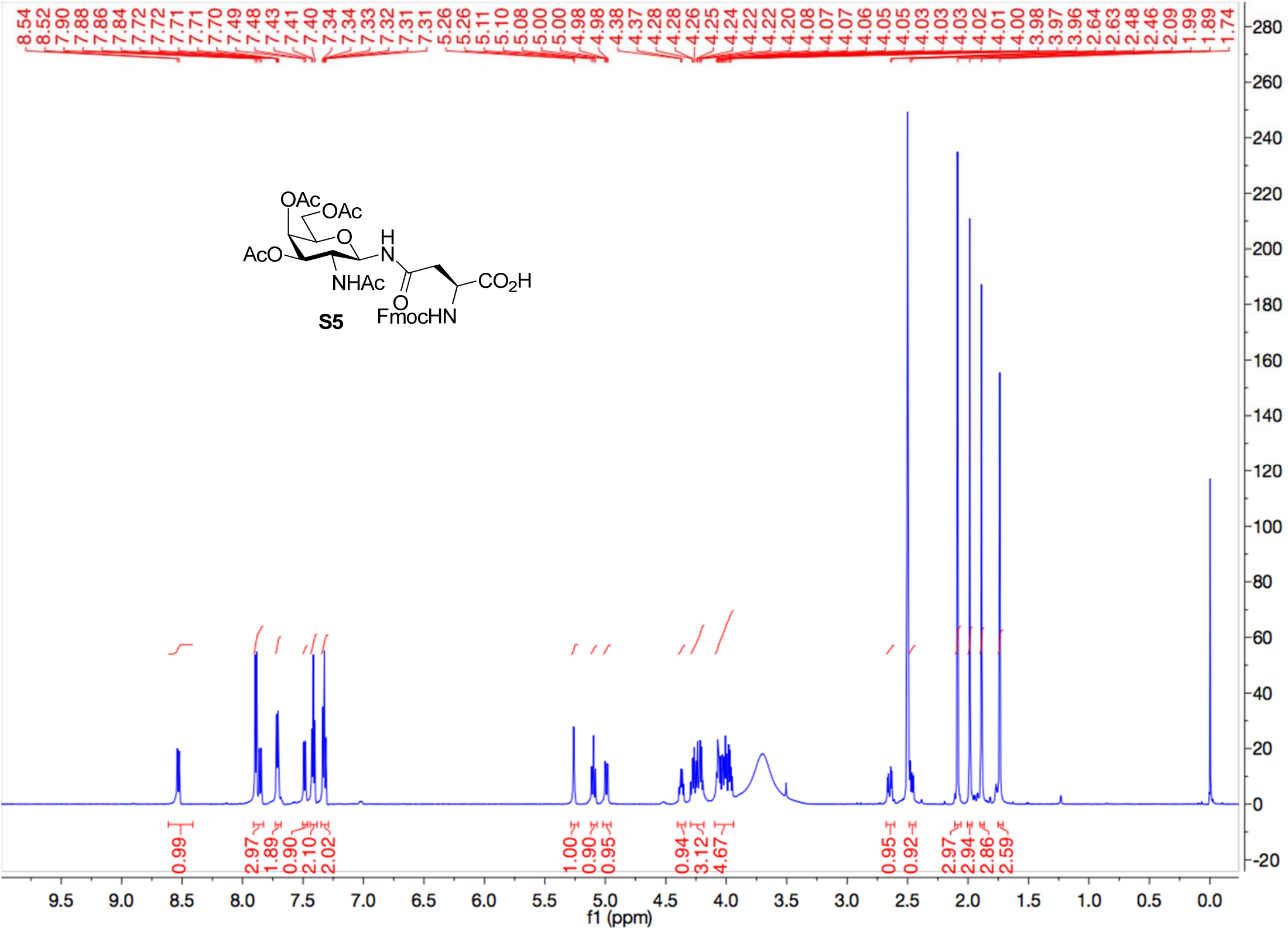

S-NMR-6 


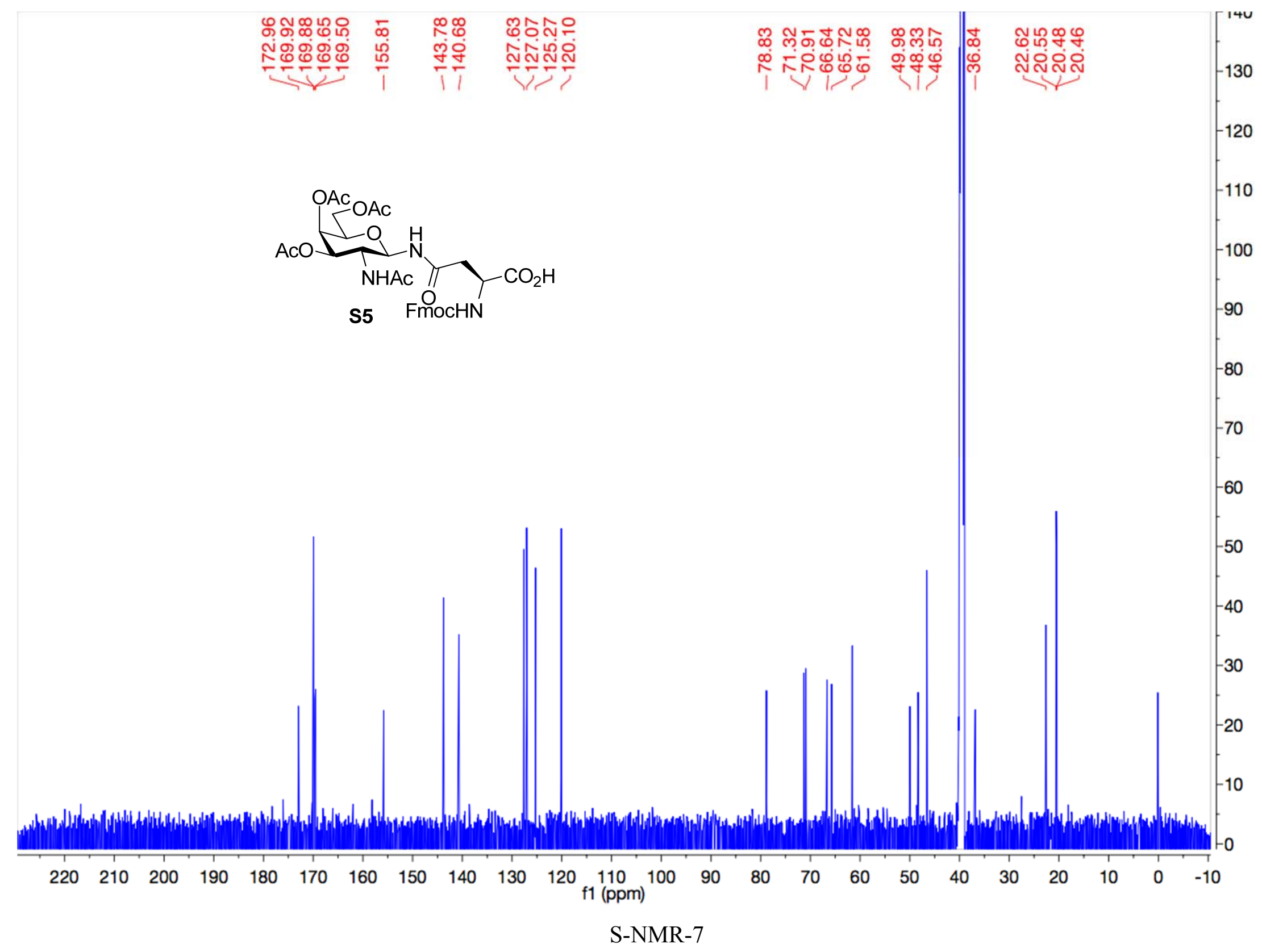




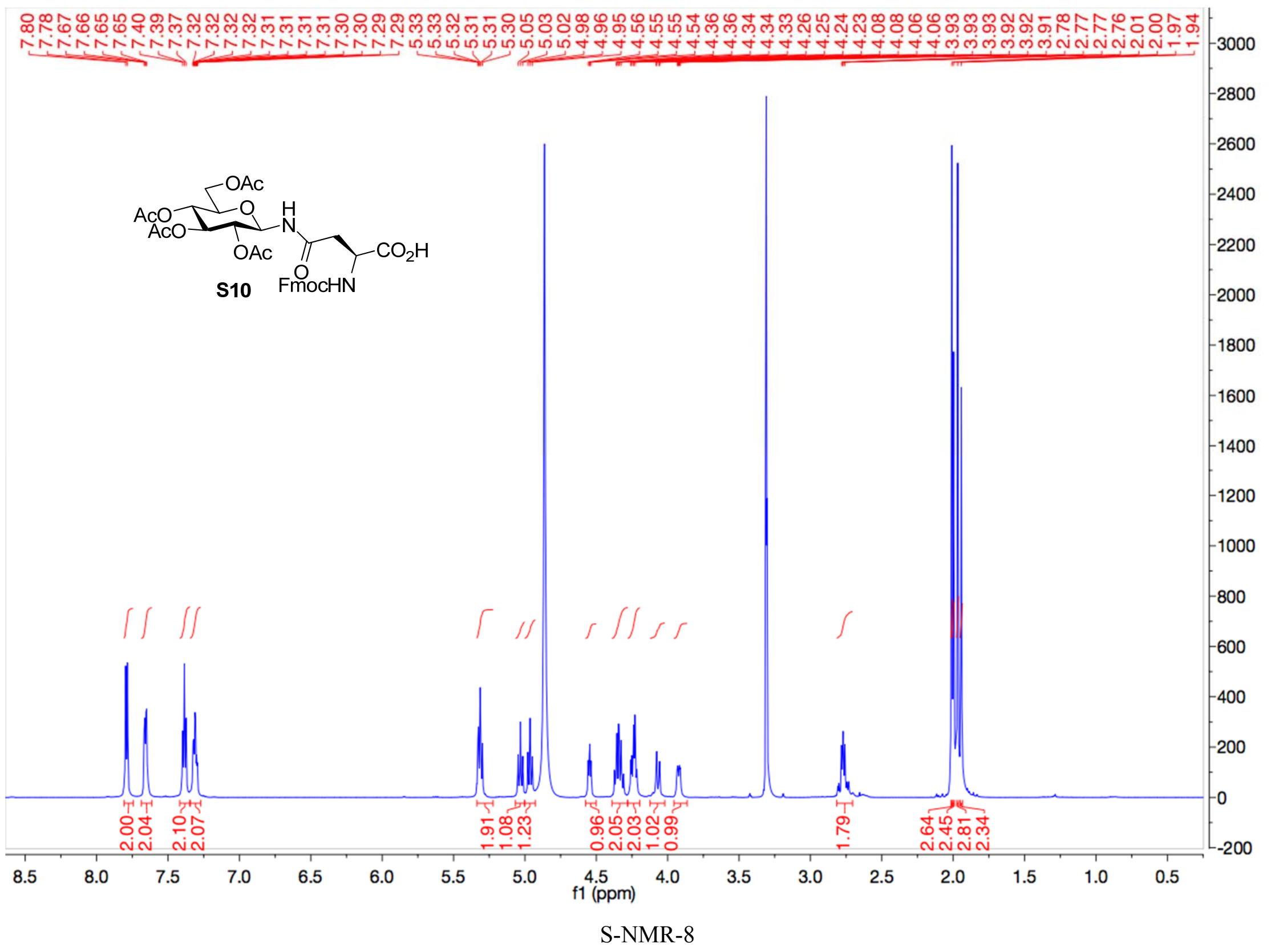




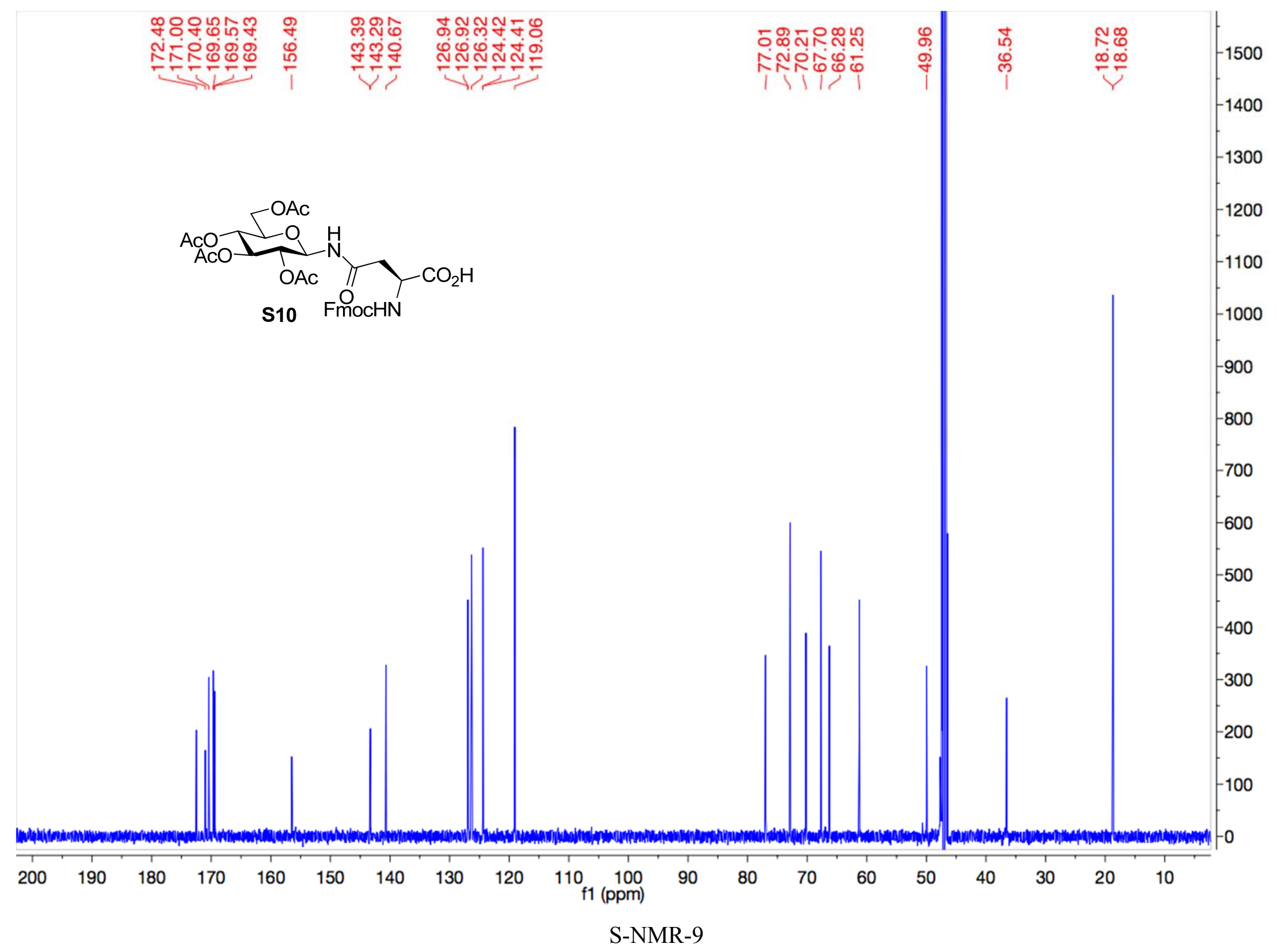




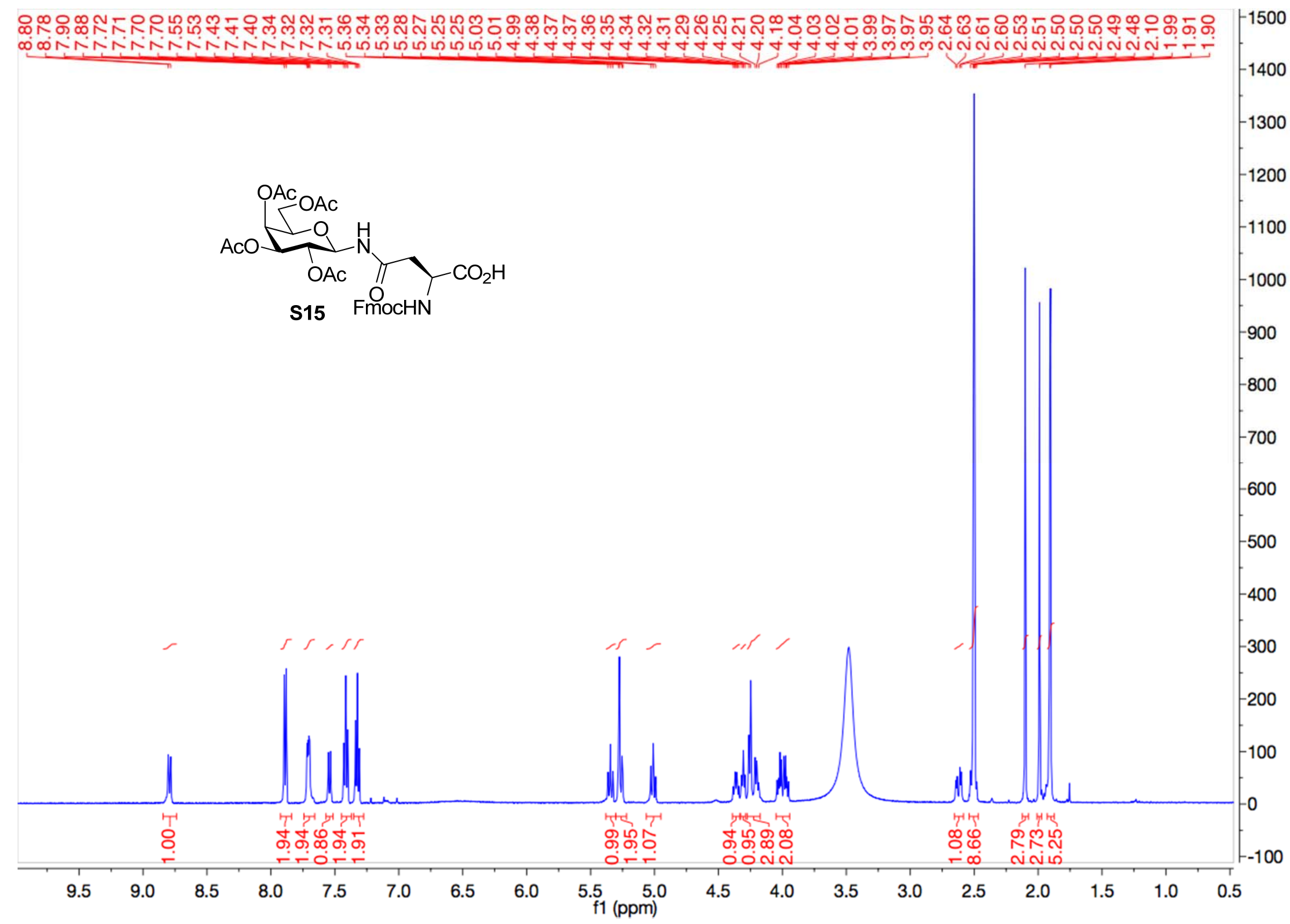

S-NMR-10 


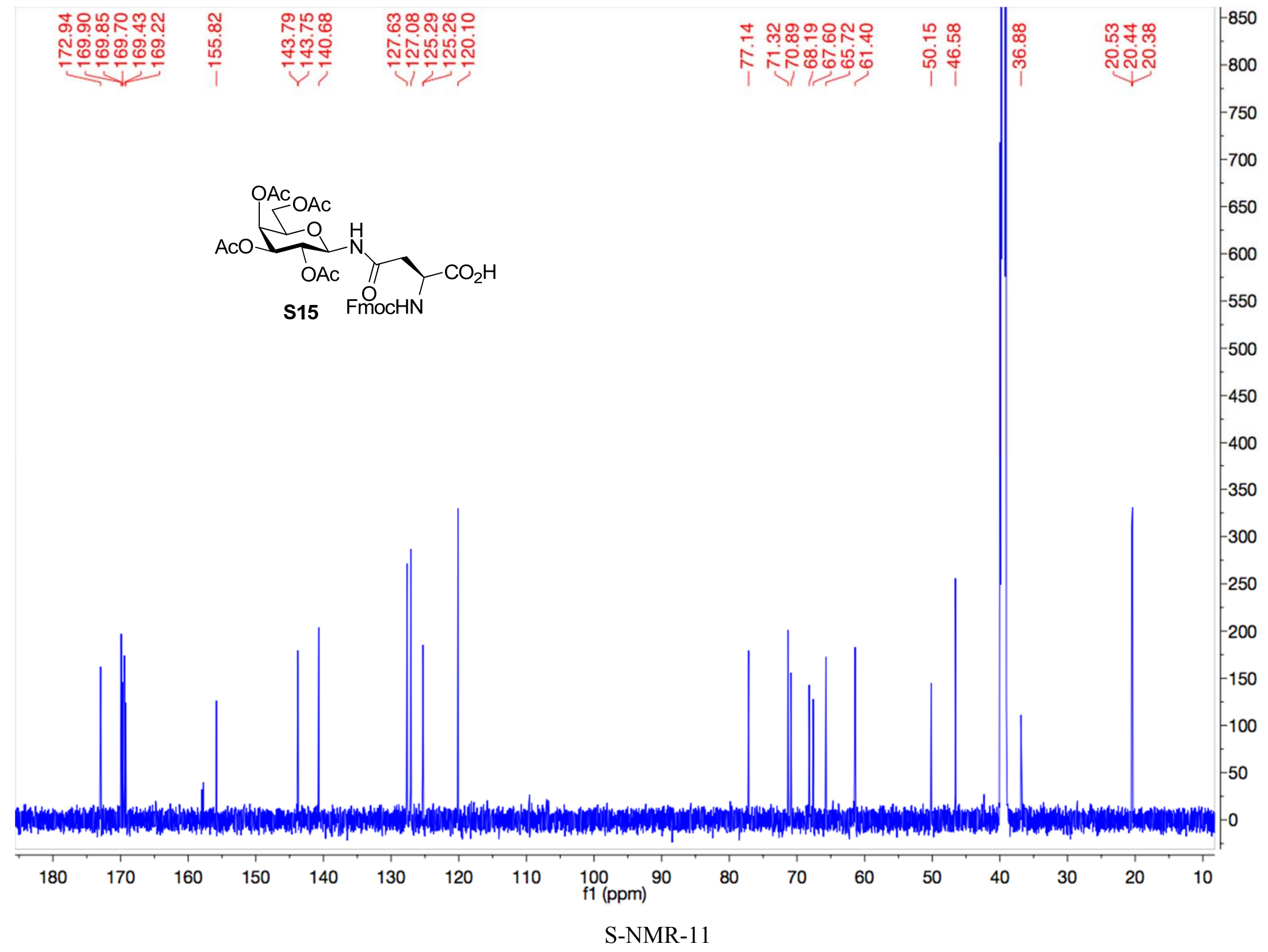




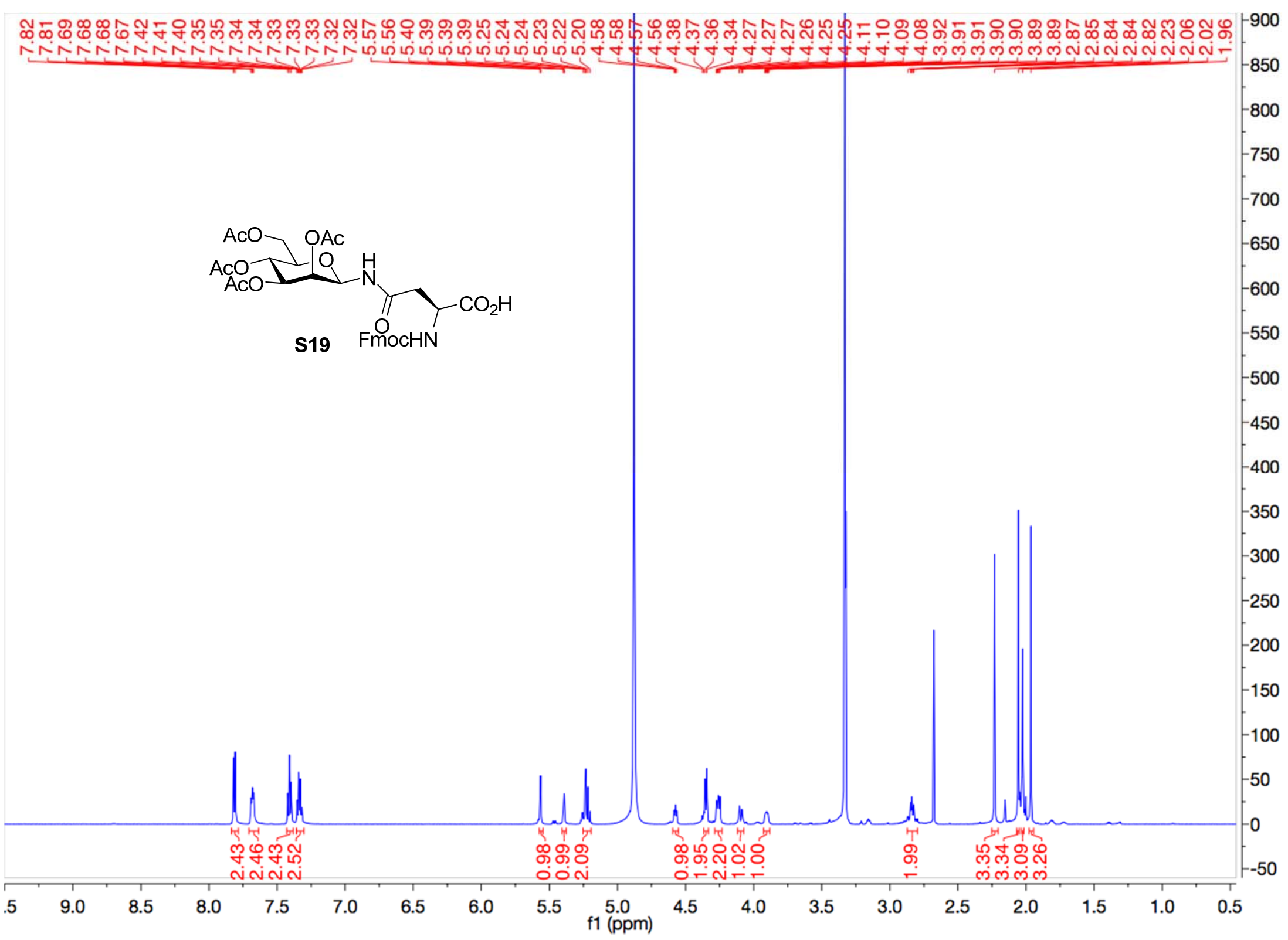

S-NMR-12 


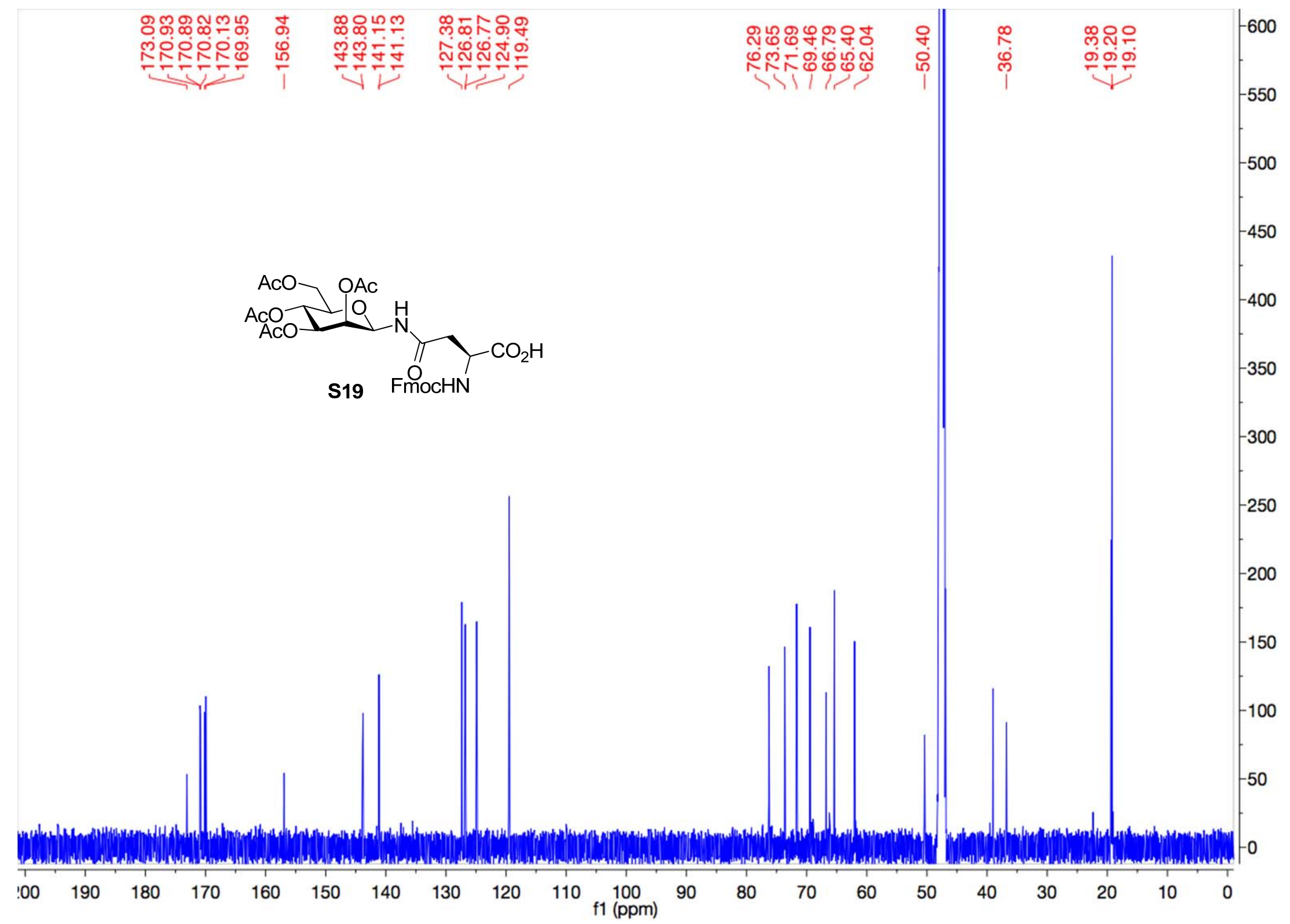

S-NMR-13 


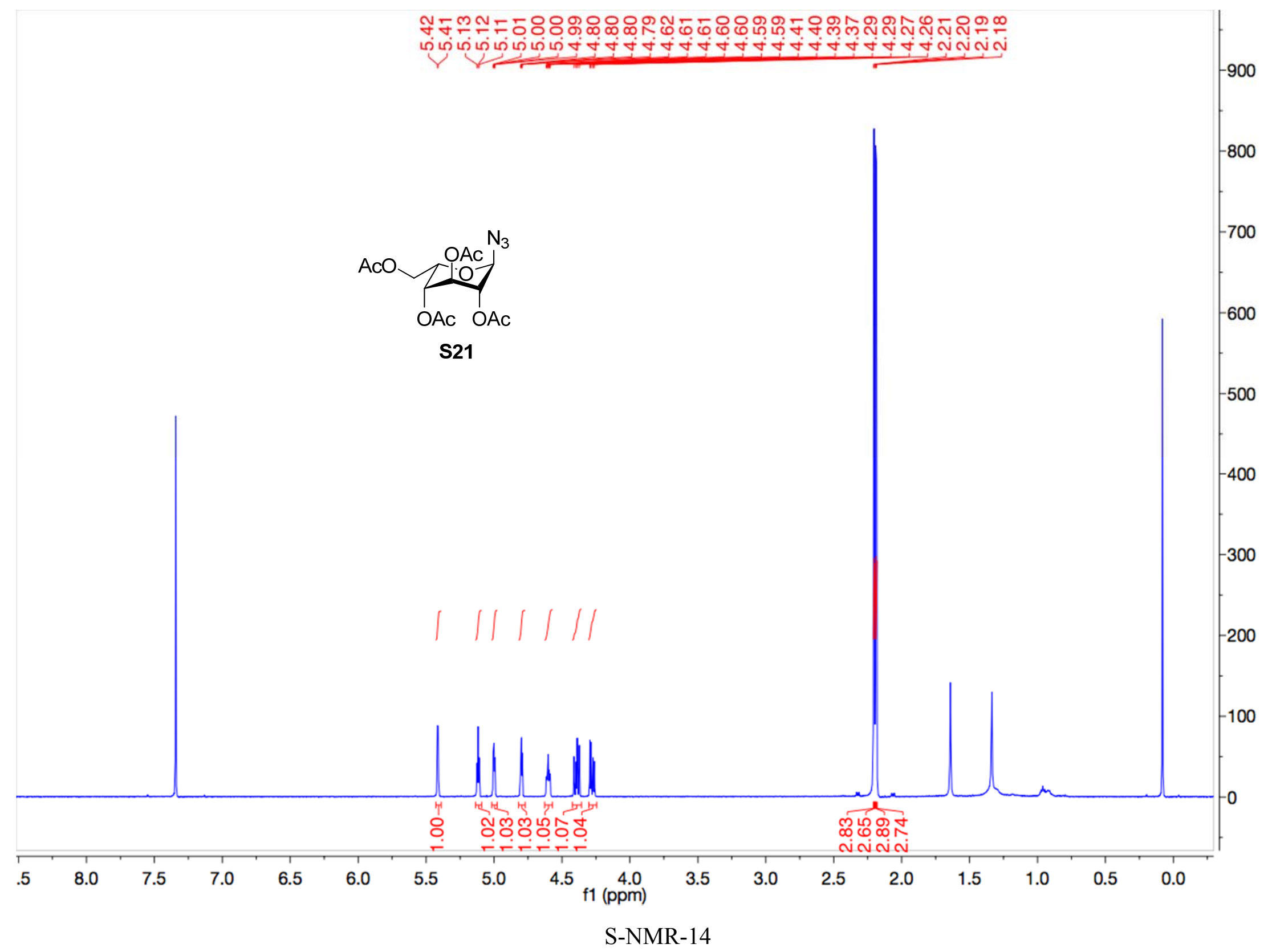




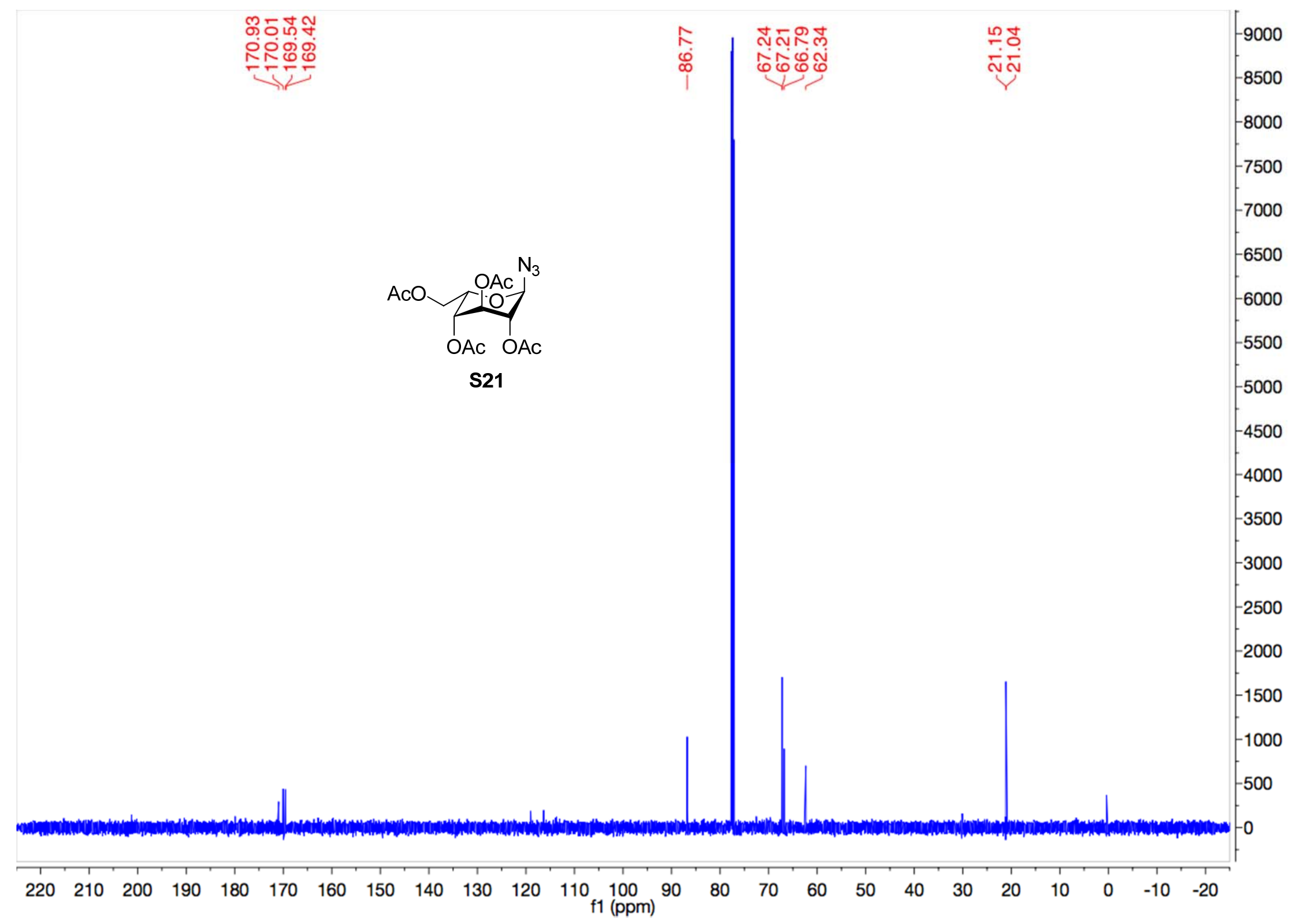

S-NMR-15 


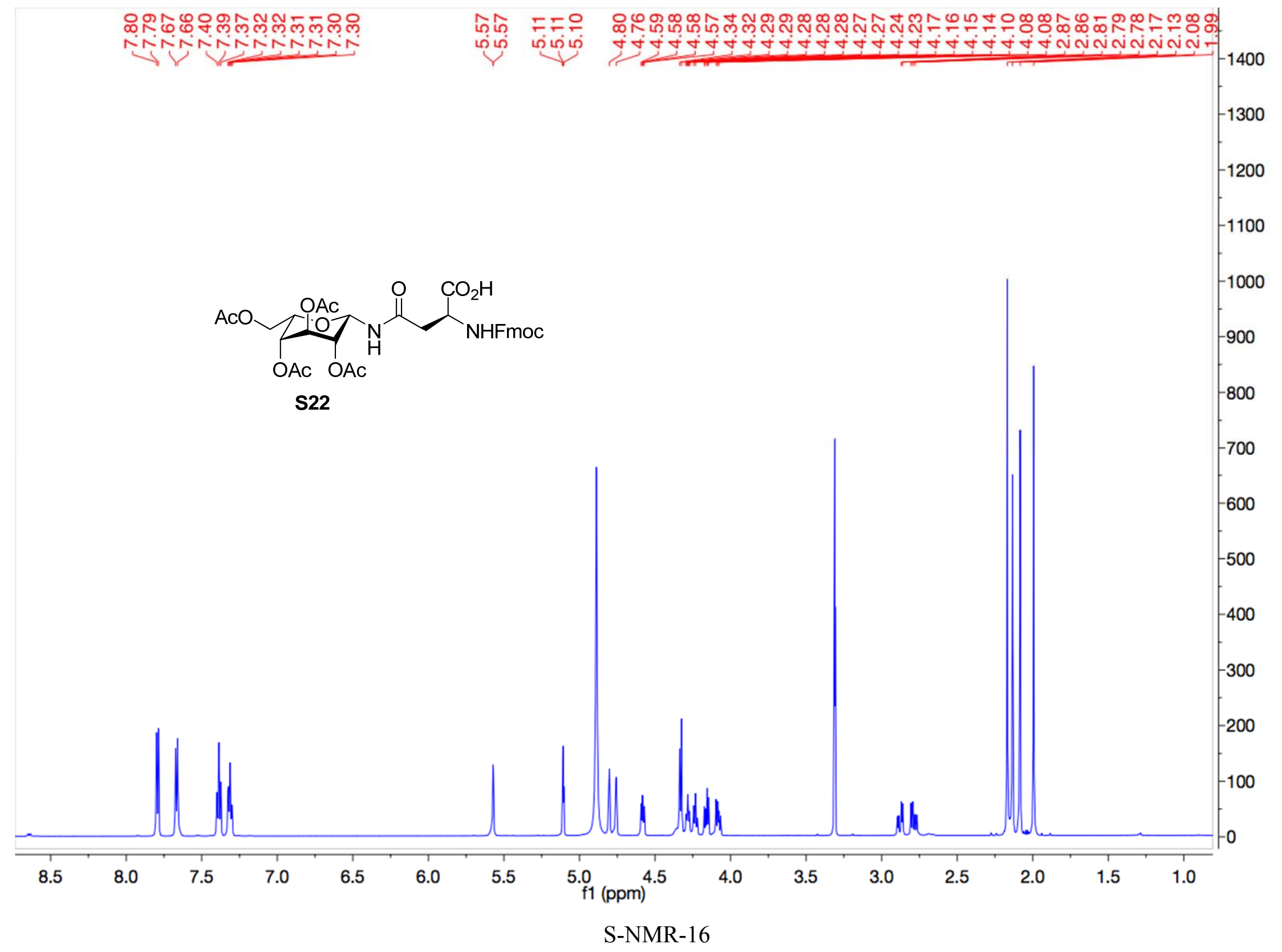




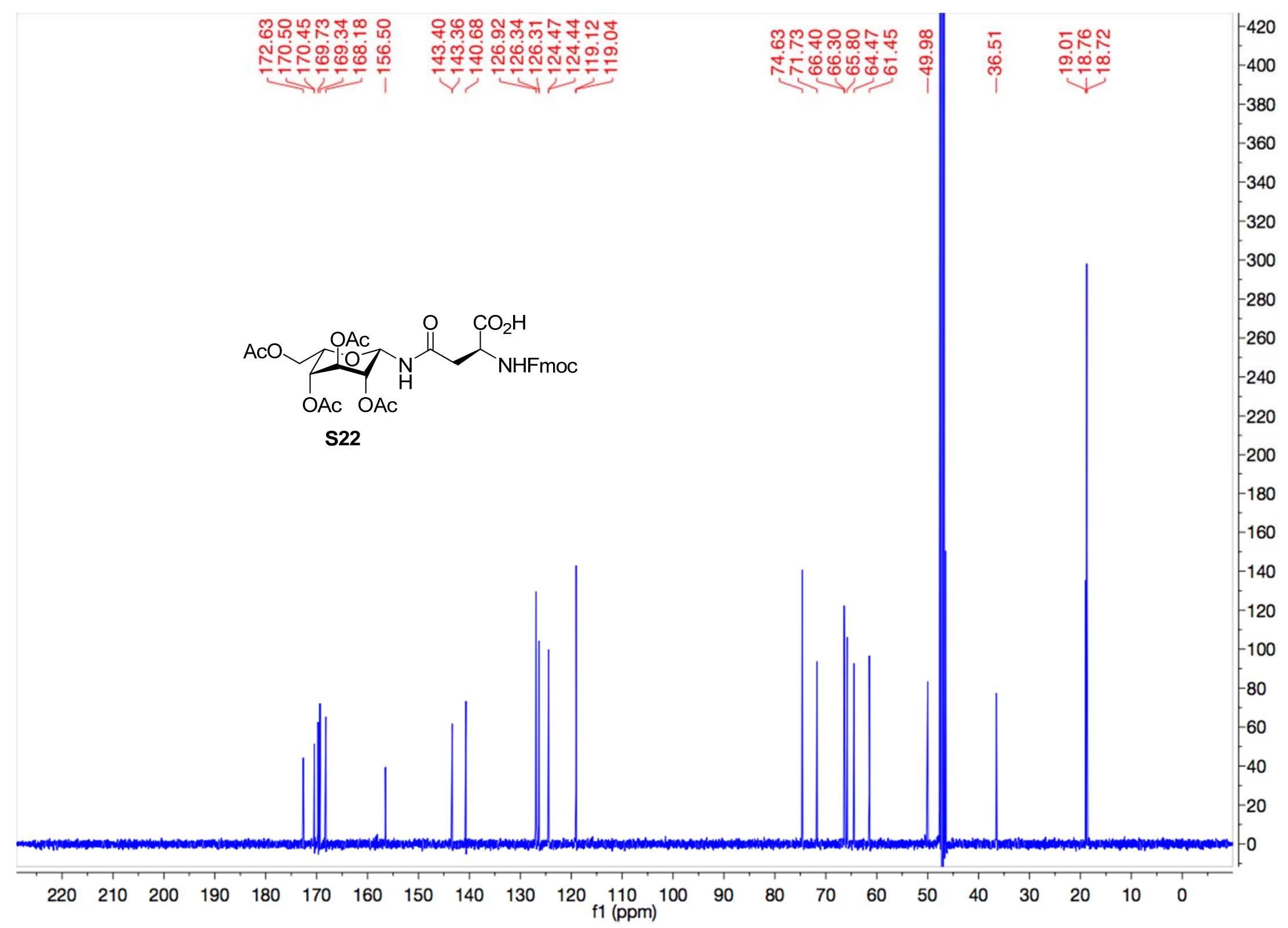

S-NMR-17 


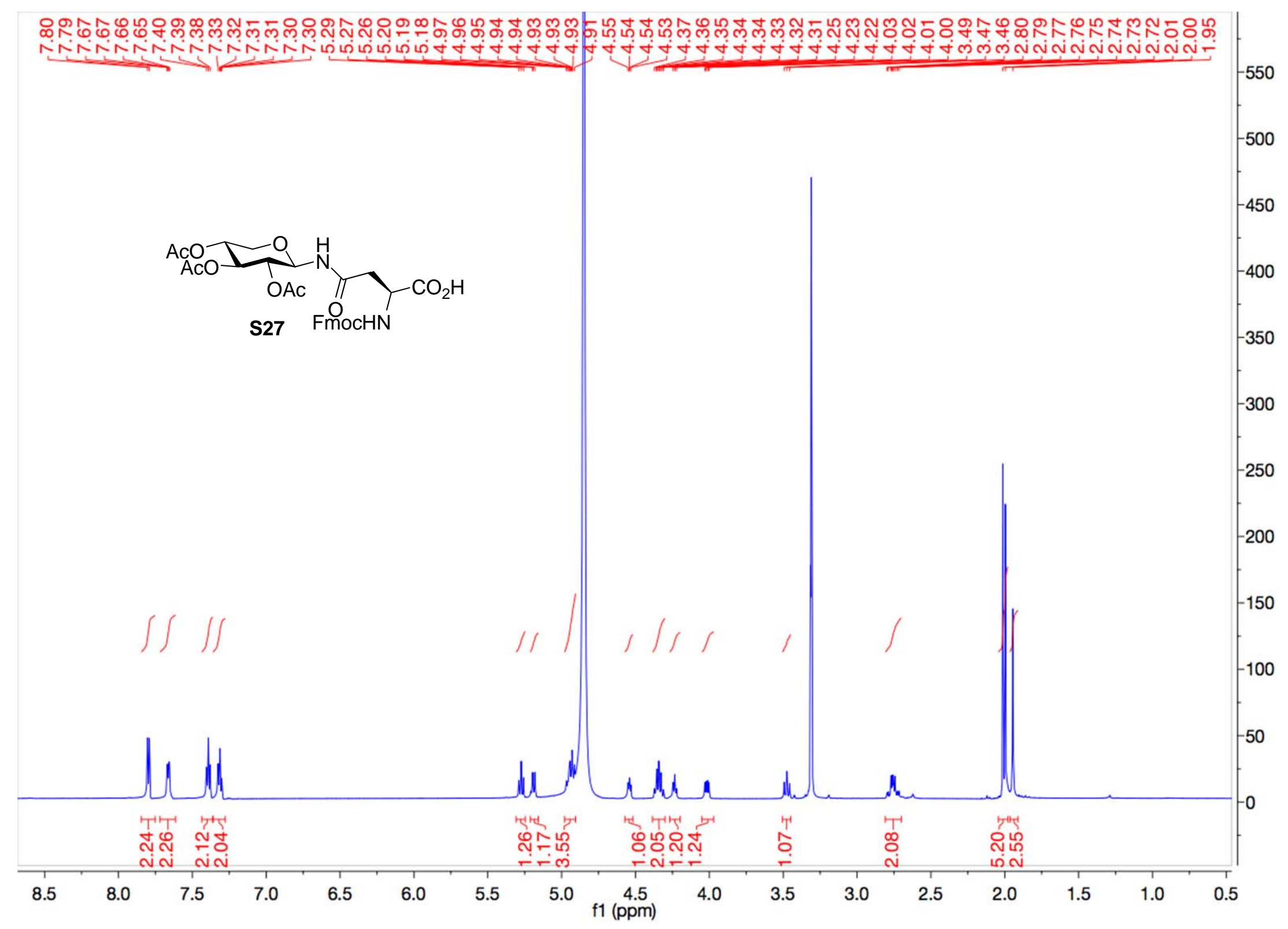

S-NMR-18 


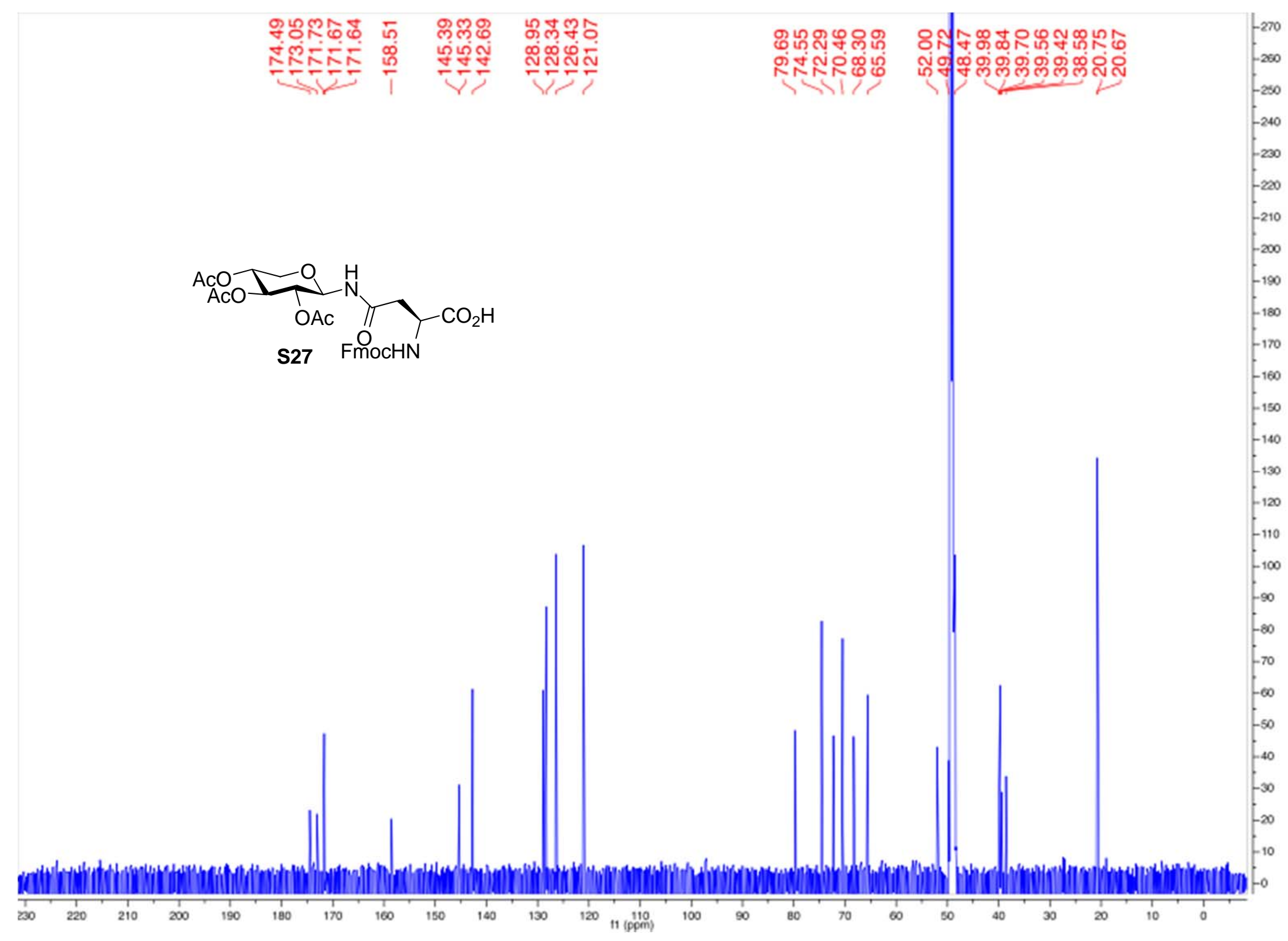

S-NMR-19 


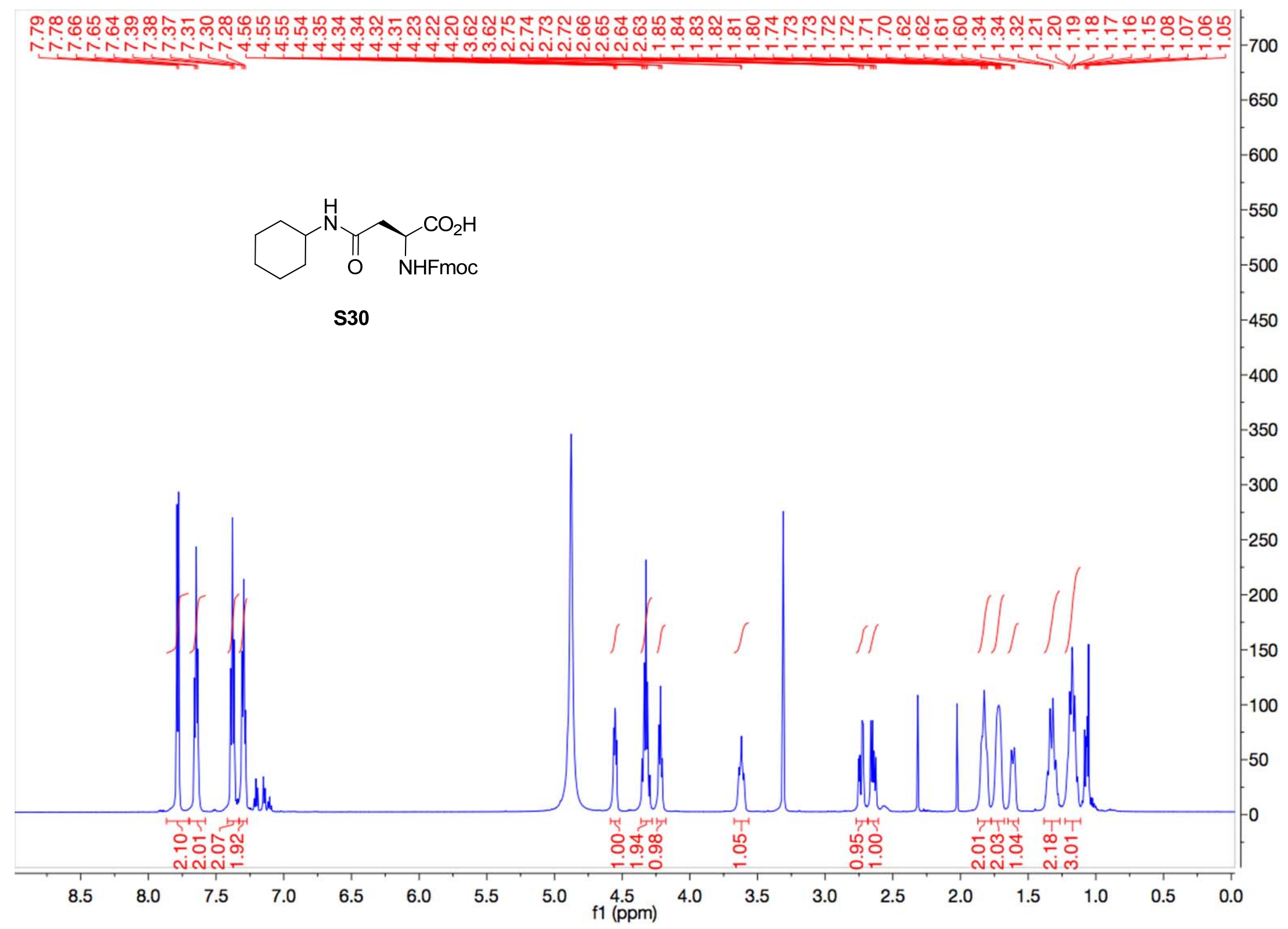

S-NMR-20 


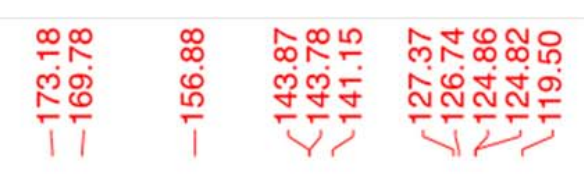

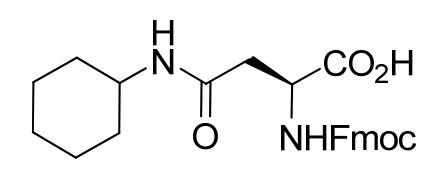

S30

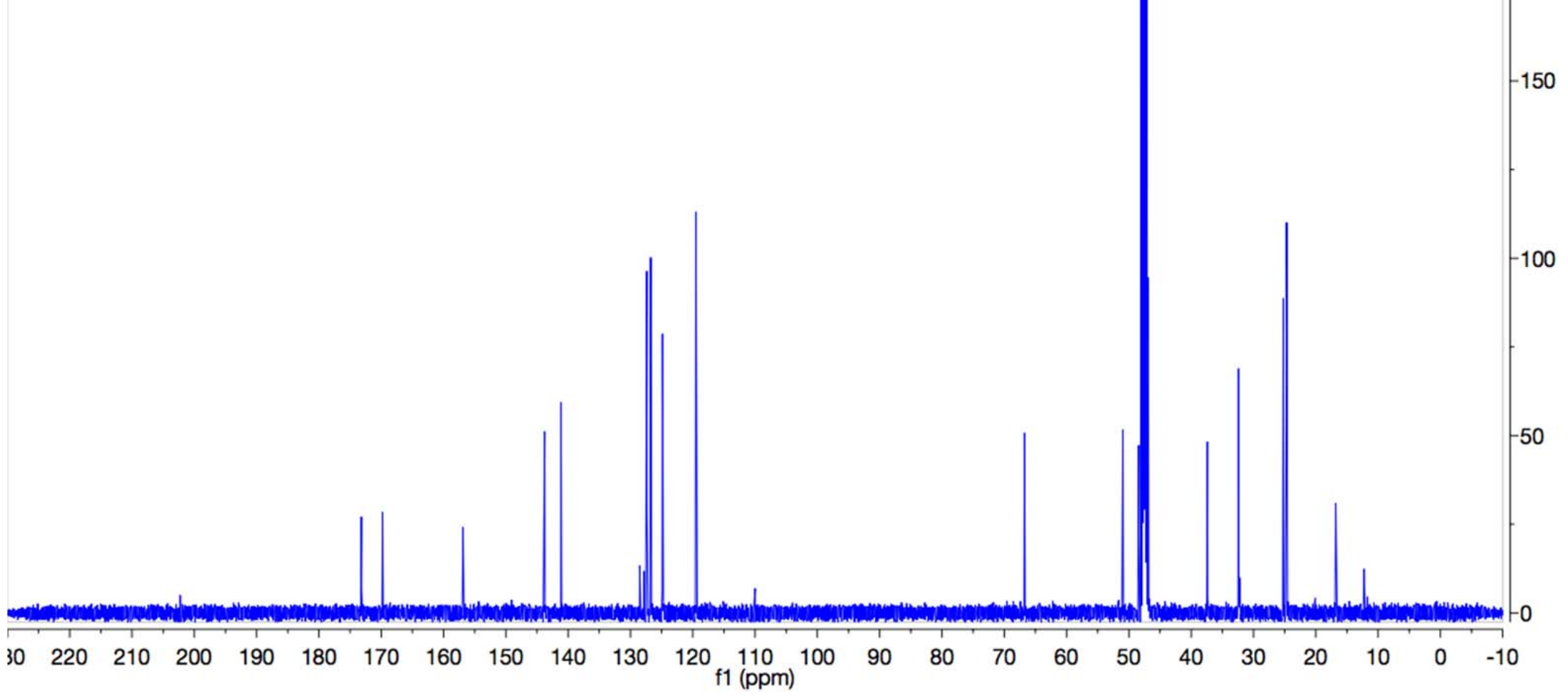

S-NMR-21 


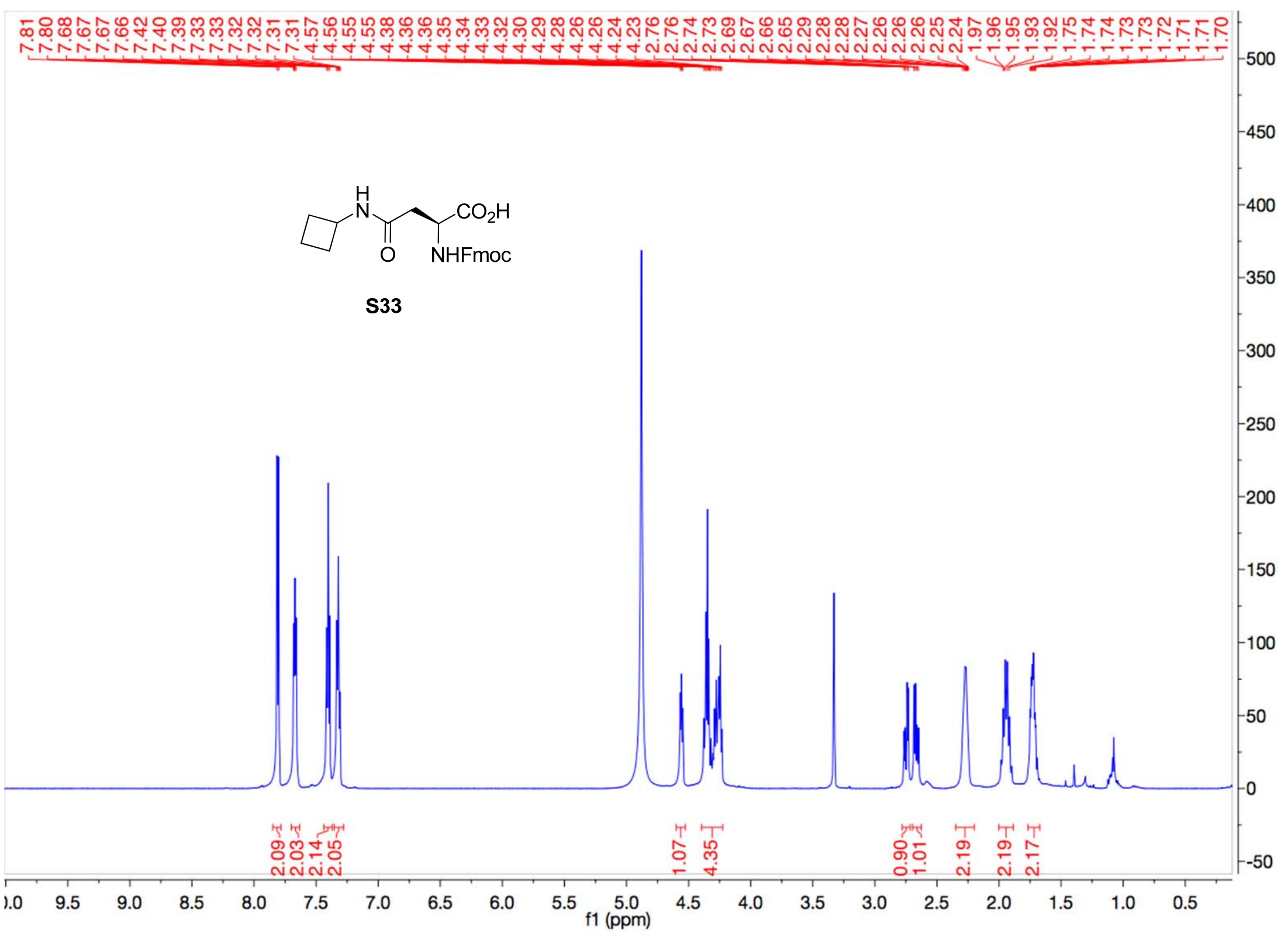

S-NMR-22 


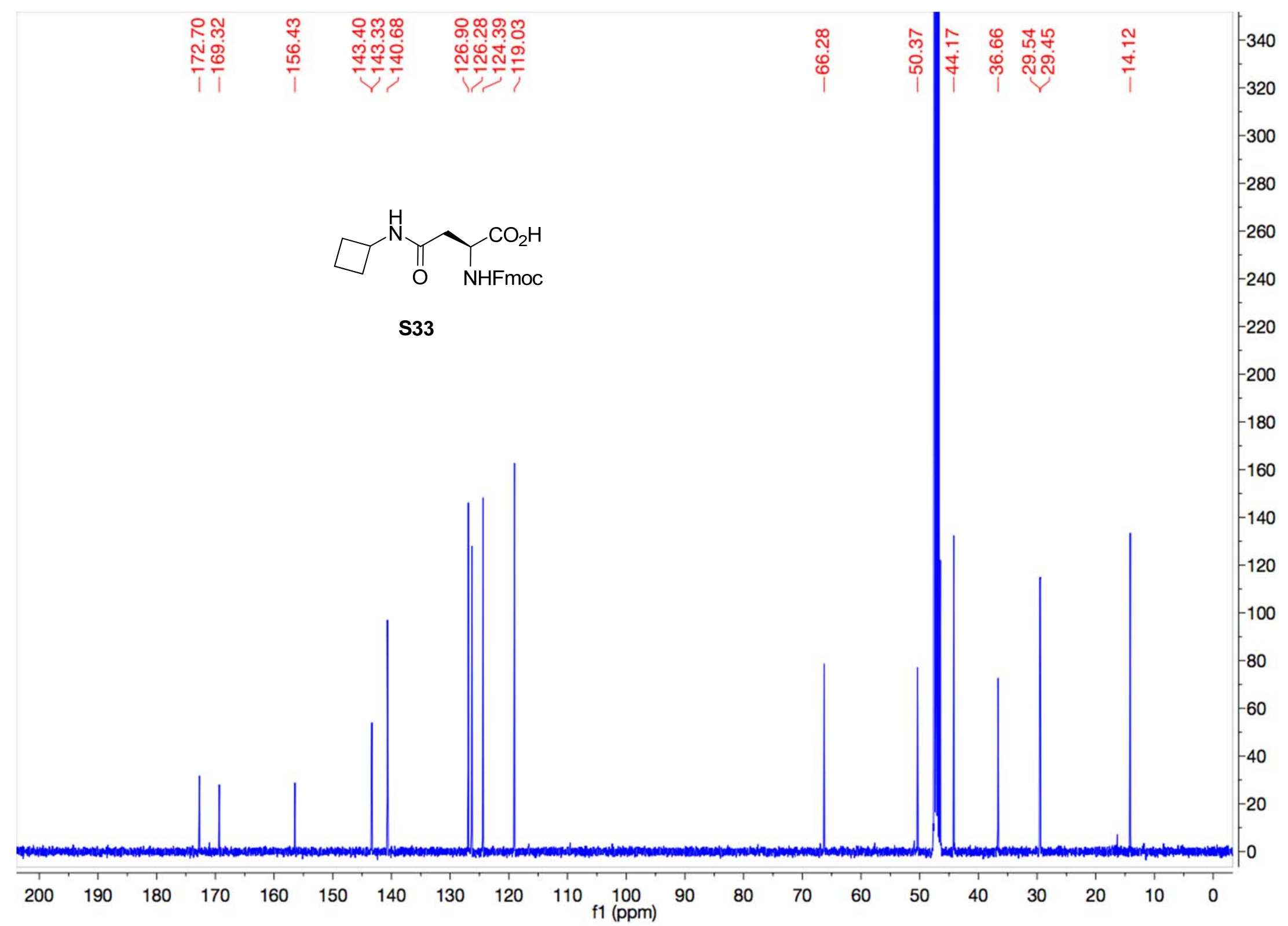

S-NMR-23 


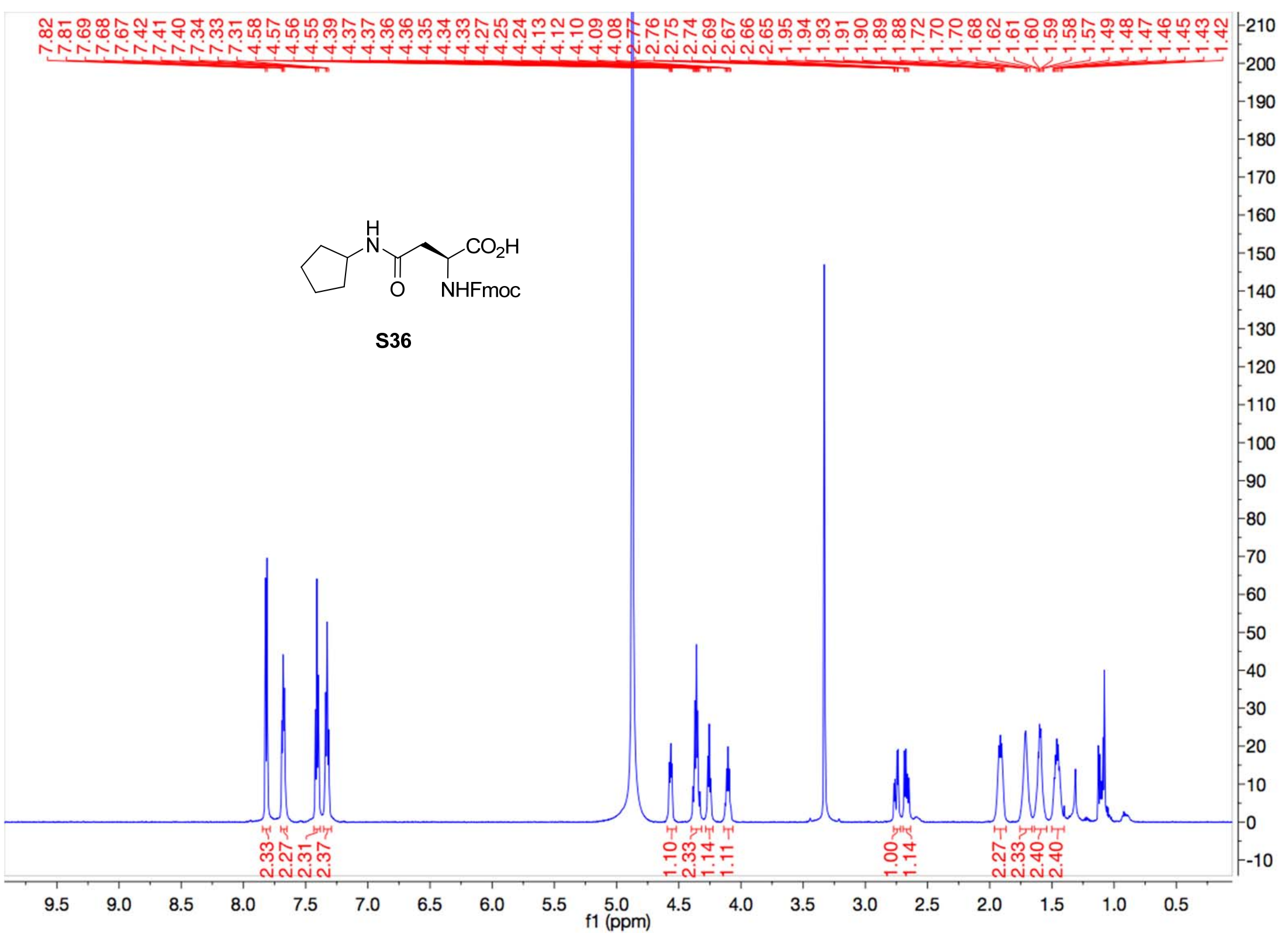

S-NMR-24 


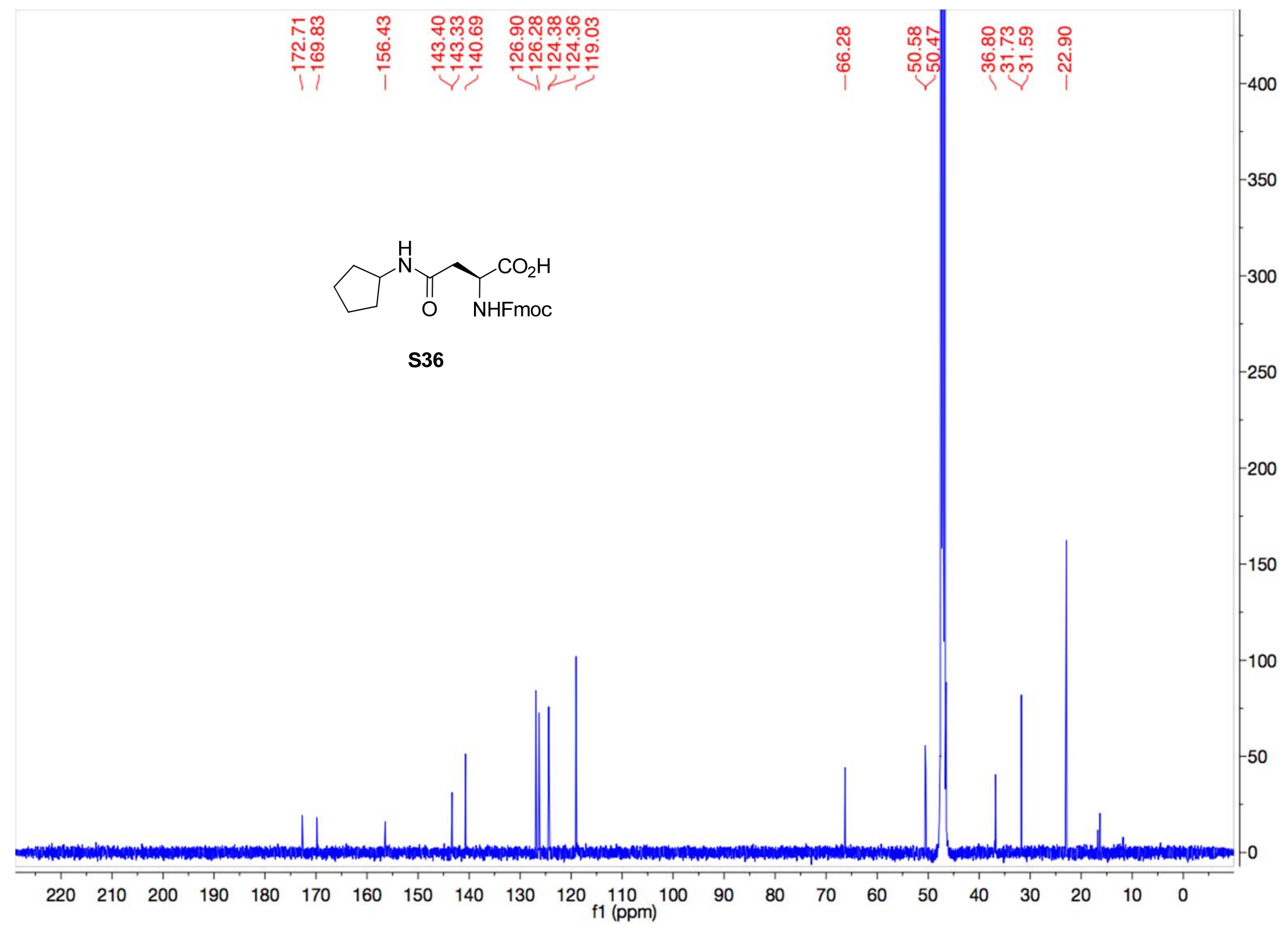

S-NMR-25 


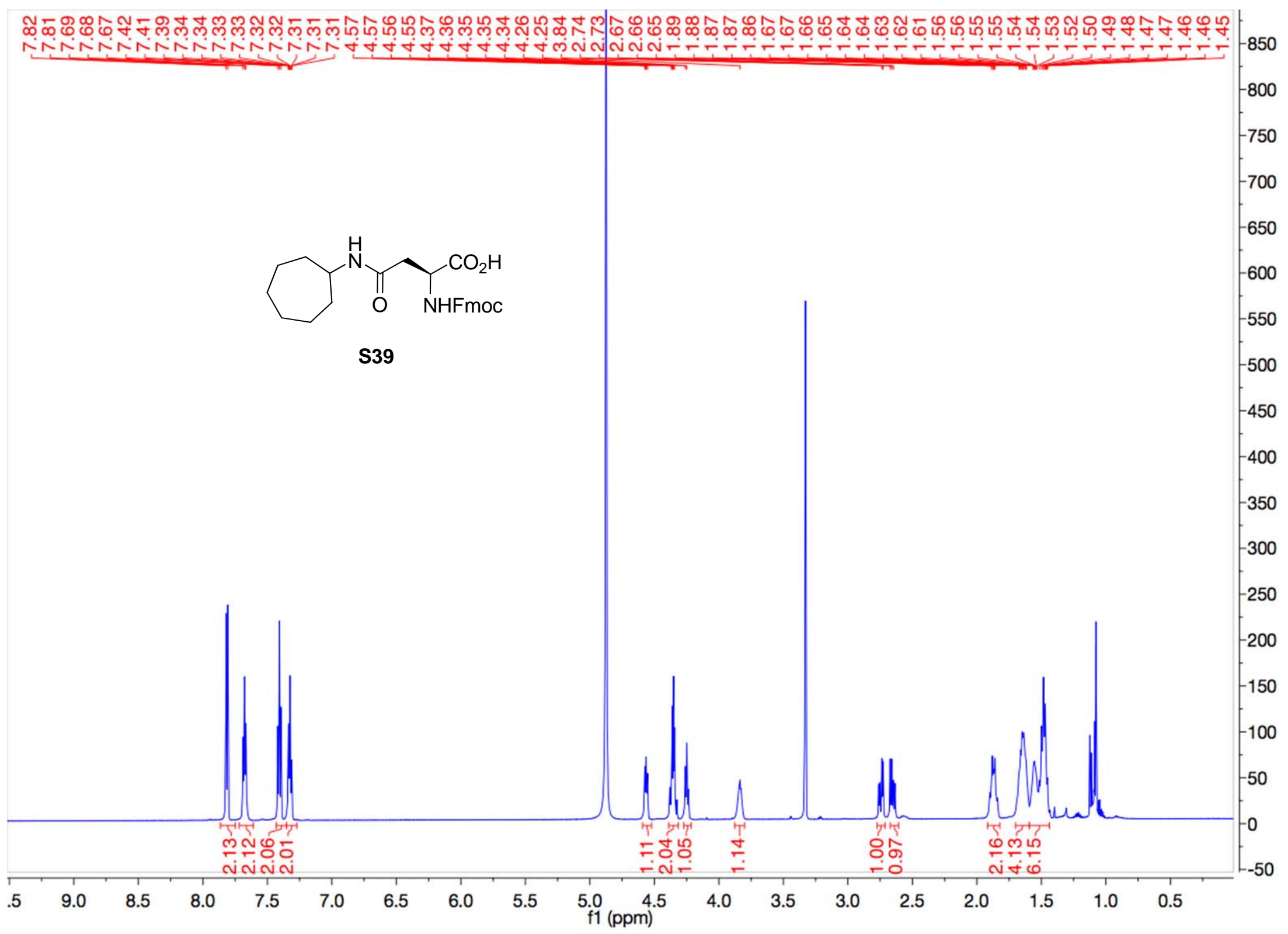

S-NMR-26 


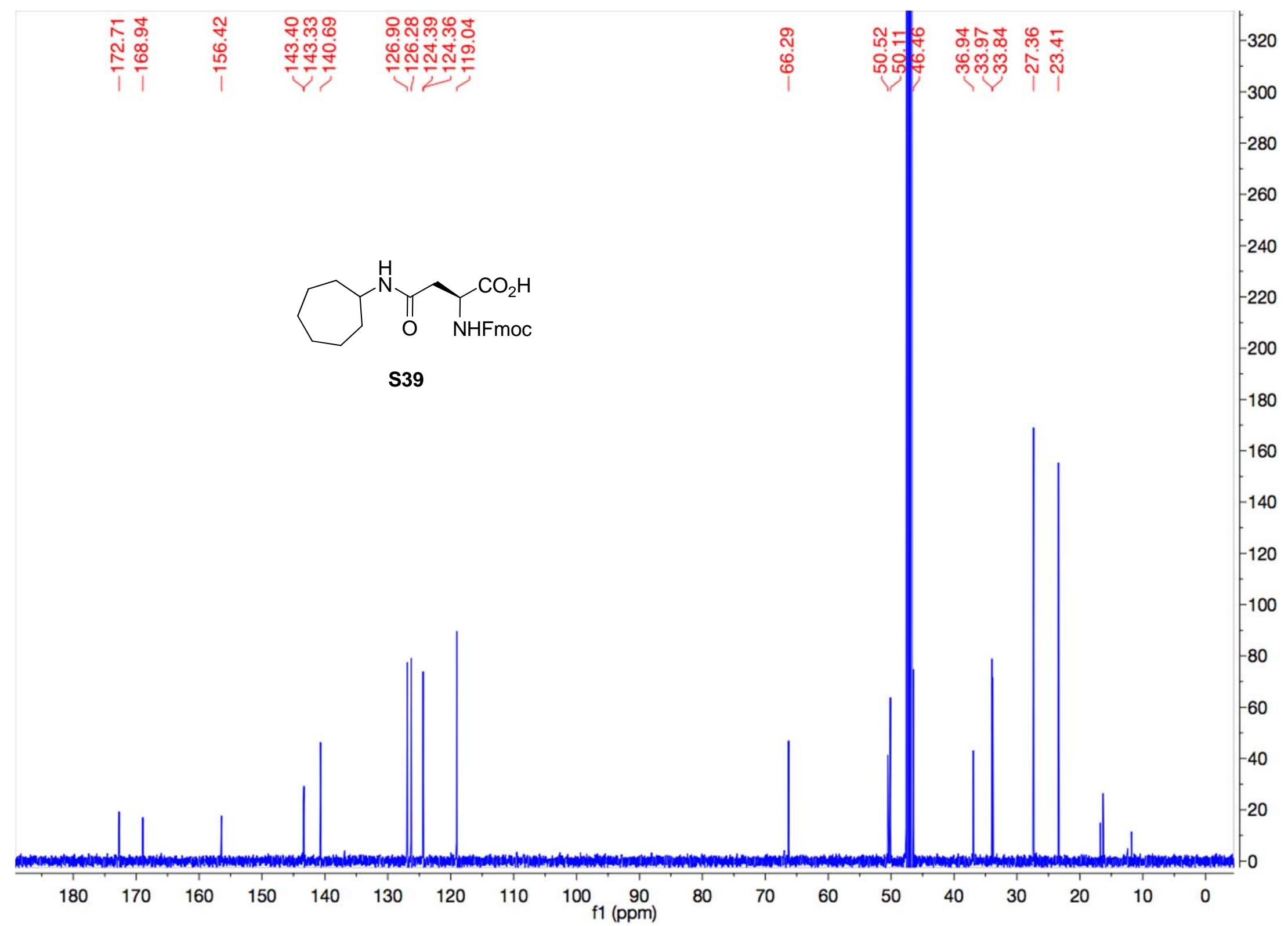

S-NMR-27 